\title{
Celecoxib exerts antitumor effects in canine mammary tumor cells via COX-2-independent mechanisms
}

\author{
DAI TAMURA*, TERUYOSHI SAITO*, KANAE MURATA, MASAFUMI KAWASHIMA and RYUJI ASANO \\ Laboratory of Veterinary Pharmacology, Nihon University College \\ of Bioresource Sciences, Fujisawa, Kanagawa 252-8510, Japan
}

Received October 21, 2014; Accepted December 5, 2014

DOI: $10.3892 /$ ijo.2015.2820

\begin{abstract}
Celecoxib plays antitumor roles via multiple mechanisms in a variety of human cancers. The aim of this study was to clarify the mechanism of action of celecoxib in canine mammary tumors. We examined the antitumor effects of celecoxib in AZACB canine mammary tumor cells expressing low levels of cyclooxygenase-2 (COX-2) to minimize the effect of COX-2 on its activity. Our data revealed that celecoxib inhibited cell proliferation mainly via COX-2-independent mechanisms. Specifically, celecoxib decreased the proportion of cells in $\mathrm{S}$ phase and increased G2/M arrest, which was associated with increased expression of the cyclin-dependent kinase inhibitors (CDKIs) p21 and $\mathrm{p} 27$. In addition, treatment with celecoxib downregulated COX-2 expression, and induced apoptosis via both the intrinsic and extrinsic pathways. These findings suggest that celecoxib might be a useful agent for the treatment of canine mammary tumors, regardless of $\mathrm{COX}-2$ expression. In the future, it might be possible to use a combination of celecoxib and other antitumor agents to treat canine mammary tumors.
\end{abstract}

\section{Introduction}

Arachidonic acids are converted into prostaglandin (PG) $\mathrm{H}_{2}$, which is the precursor of eicosanoids, including PGs, prostacyclin $\left(\mathrm{PGI}_{2}\right)$, and thromboxanes (TXs), in a reaction that is catalyzed by cyclooxygenases (COXs). There are three COX isoenzymes: COX-1, -2 , and -3 . COX-1 is constitutively expressed in most tissues, and plays an important role in protecting the gastric mucosa, regulating platelet aggregation, and maintaining renal blood flow (1). COX-3

Correspondence to: Dr Teruyoshi Saito, Laboratory of Veterinary Pharmacology, Nihon University College of Bioresource Sciences, 1866 Kameino, Fujisawa, Kanagawa 252-8510, Japan

E-mail: saitou.teruyoshi@nihon-u.ac.jp

*Contributed equally

Key words: cyclooxygenase-2, celecoxib, apoptosis, intrinsic pathway, extrinsic pathway, canine mammary tumor was initially identified as an alternatively spliced variant of COX-1 in dogs (2). Although COX-3 is a potential target of the antipyretic and analgesic effects of acetaminophen, its detailed function remains unclear (2). In contrast, it is known that cyclooxygenase-2 (COX-2) is induced by various stimuli such as pro-inflammatory cytokines during inflammation or the initiation and progression of cancer. In cancer, it is suspected that COX-2 plays an important role in angiogenesis, invasion, apoptosis resistance, immune evasion, and drug resistance (3-9). Therefore, it might play a role in the antitumor effects of non-steroidal anti-inflammatory drugs (NSAIDs). Selective COX-2 inhibitors have been developed to reduce gastrointestinal dysfunction, and for chemotherapy or chemoprevention in various human cancers. The antitumor effects of selective COX-2 inhibitors are exerted via diverse means, including COX-2-dependent and -independent mechanisms and the activation of intrinsic and extrinsic apoptotic pathways. However, the detailed mechanism of action of the antitumor effects of selective COX-2 inhibitors in various cancers remains controversial.

Canine mammary tumors are the most common tumors in female dogs without contraception, and approximately half of all cases are malignant. However, it is difficult to diagnose malignant canine mammary tumors histopathologically (10). Accordingly, several studies have explored molecular markers to diagnose or treat malignant canine mammary tumors. Among these, COX-2 has received significant attention as a diagnostic and therapeutic target (11-13). Furthermore, previous reports suggested that canine mammary tumors could be a suitable model for studying human breast cancer (14).

COX-2 overexpression has been reported in human breast cancer (15). Similarly, COX-2 expression was elevated in canine mammary tumors compared with normal mammary tissue (16). In particular, a previous study demonstrated that although no expression was detected in the normal mammary gland, COX-2 was expressed in 56 and 24\% of adenocarcinoma and adenoma samples, respectively (16). This report also suggested that COX-2-positive tumor cells might have a higher malignant tendency (16). Furthermore, a previous study reported a correlation between vascular endothelial growth factor (VEGF) and COX-2 levels; the enhanced production of VEGF resulted in increased intra-tumoral microvessel density (17). These findings suggest that COX-2 
might be a potential marker for poor prognosis and a target for chemotherapy in canine mammary tumors. We previously demonstrated the usefulness of selective COX-2 inhibitors as therapeutic agents in canine mammary tumor (CF33) cells, which express high levels of COX-2 (18). However, the detailed mechanism of action of celecoxib in canine mammary tumor is still not completely understood.

Our previous study suggested that selective COX-2 inhibitors exert potential antitumor effects via both COX-2-dependent and -independent mechanisms (18). Accordingly, the aim of this study was to explore the detailed mechanism of action of selective COX-2 inhibitors in canine mammary tumor cells. We analyzed their antitumor effects in AZACB canine mammary tumor cells, which express low levels of COX-2, to minimize the effect of COX-2. Furthermore, we used three different inhibitors (celecoxib, etodolac, and meloxicam) that are highly selective for COX-2; these inhibitors have potential clinical utility as analgesics and anti-inflammatory agents in osteoarthritic dogs $(19,20)$.

\section{Materials and methods}

Chemicals. We used meloxicam, etodolac, and celecoxib to assess the antitumor effect of selective COX-2 inhibitors. Celecoxib and etodolac were purchased from Sigma-Aldrich (Tokyo, Japan), and meloxicam was obtained from Wako Pure Chemicals Industries, Ltd., (Osaka, Japan). 2,5-Dimethyl-celecoxib (DMC), a structural analog of celecoxib, was purchased from Sigma-Aldrich. All the drugs were dissolved in $100 \%$ DMSO (Wako Pure Chemicals Industries, Ltd.) at different concentrations and stored at $-20^{\circ} \mathrm{C}$. Control cells were treated with DMSO at a final concentration of $0.1 \%$, whereas parent cells were untreated. The following antibodies were used in the current study: anti-COX-2 (Abcam, Tokyo, Japan), anti- $\beta$-actin (Sigma-Aldrich), anti-p27 kip1 (BD Transduction Laboratories, Tokyo, Japan), anti-Bax (Millipore, Billerica, MA, USA), and anti-Bid (Abnova, Taipei, Taiwan). All other antibodies were purchased from Cell Signaling Technology, Inc. (Tokyo, Japan). The inhibitors caspase-8 (Z-IETD-FMK) and caspase-9 (Z-LEHD-FMK) were obtained from R\&D Systems (Minneapolis, MN, USA), and were dissolved in $100 \%$ DMSO and stored at $-20^{\circ} \mathrm{C}$.

Cell lines and culture conditions. AZACB cells were purchased from Primary Cell Co., Ltd. (Hokkaido, Japan), CF33, and CF41.MG cells were purchased from American Type Culture Collection (Manassas, VA, USA). The cells were cultured in Dulbecco's modified Eagle's medium (Nissui Pharmaceutical Co., Ltd., Tokyo, Japan) containing $10 \%$ heat-inactivated fetal bovine serum (FBS), $4 \mathrm{mM}$ L-glutamine, $10 \mathrm{mg} / \mathrm{ml}$ streptomycin, and $10,000 \mathrm{U} / \mathrm{ml}$ penicillin $\mathrm{G}$ at $37^{\circ} \mathrm{C}$ in a $5 \% \mathrm{CO}_{2}$ incubator. AZACB, CF33, and CF41.MG cells were cultured as described previously $(18,21,22)$.

Western blotting. Cells were lysed in radioimmunoprecipitation assay buffer containing $25 \mathrm{mM}$ Tris- $\mathrm{HCl}(\mathrm{pH} 7.6)$, $150 \mathrm{mM} \mathrm{NaCl}, 1 \% \mathrm{NP}-40,0.1 \%$ SDS, $1 \%$ sodium deoxycholate, and various protease inhibitors $(1 \mu \mathrm{g} / \mathrm{ml}$ leupeptin, $1 \mu \mathrm{g} / \mathrm{ml}$ pepstatin, $1 \mu \mathrm{g} / \mathrm{ml}$ aprotinin, $1 \mathrm{mM}$ dithiothreitol,
$1 \mathrm{mM} \mathrm{NaVO}$, and $0.5 \mathrm{mM}$ phenylmethylsulfonyl fluoride). Whole cell lysates were prepared as described previously (23). The protein concentrations of the cell lysates were then quantified using the Bradford method with a Pierce ${ }^{\circledR}$ BCA Protein Assay kit (Pierce Biotechnology, Inc., Rockford, IL, USA). Total cell lysates (15-25 $\mu \mathrm{g}$ ) were boiled for $5 \mathrm{~min}$ in 2X Laemmli sample loading buffer, and were then separated by SDS-PAGE on $12 \%$ (p27, Bax, Bim, and Bid) and $10 \%$ (COX-2) gels. The gels were then transferred to polyvinylidene difluoride membranes (Bio-Rad Laboratories, Tokyo, Japan). The expression of specific proteins was detected by electrochemiluminescence using WesternBright Quantum or WesternBright Sirius (Advansta, Menlo Park, CA, USA), and observed using ChemiDoc XRS (Bio-Rad Laboratories).

Cell viability assays. AZACB and CF33 cells were plated into 96-well plates (BD Falcon; Nippon Becton Dickinson, Tokyo, Japan) at a density of $2.5 \times 10^{3}$ and $1 \times 10^{3}$ cells/well, respectively. After $24 \mathrm{~h}$, the cells were treated with different concentrations of selective COX-2 inhibitors or DMC. Twenty-four hours after treatment, cell number was determined using a WST-8 assay (Cell Counting kit-8; Dojindo Laboratories, Kumamoto, Japan) according to the manufacturer's instructions. The absorbance was measured at $450 \mathrm{~nm}$ using a Benchmark Plus microplate reader (Bio-Rad Laboratories). The experiment was performed using five replicates. As a control, it was confirmed that there were no changes in cell viability before drug treatment (day 0).

Measurements of prostaglandin $E_{2}\left(P G E_{2}\right)$. AZACB cells were plated into 100-mm tissue culture dishes (BD Falcon; Nippon Becton Dickinson) at a density of $9.0 \times 10^{5}$ cells/dish. After $24 \mathrm{~h}$, the cells were treated with $100 \mu \mathrm{M}$ celecoxib in culture medium containing 2 or $10 \%$ FBS. Twenty-four hours later, culture media samples were collected. They were then centrifuged immediately at $500 \mathrm{x} \mathrm{g}$ for $5 \mathrm{~min}$ at $4^{\circ} \mathrm{C}$ to remove cells or debris, and the supernatants were harvested. The concentration of $\mathrm{PGE}_{2}$ in the culture medium was measured using a $\mathrm{PGE}_{2}$ enzyme immunoassay kit - Monoclonal (Cayman Chemical Co., Ann Arbor, MI, USA) following the manufacturer's instructions. The absorbance at $405 \mathrm{~nm}$ was measured using a Benchmark Plus microplate reader (Bio-Rad Laboratories). The experiment was performed in triplicate.

Flow cytometric cell cycle analysis. AZACB cells were seeded at a density of $5.0 \times 10^{5}$ cells in $100-\mathrm{mm}$ tissue culture dishes (BD Falcon; Nippon Becton Dickinson). After $24 \mathrm{~h}$ of exposure to selective COX-2 inhibitors $(10,25,50$ and $100 \mu \mathrm{M}$ meloxicam and etodolac, and 10, 25, 45, 50, 75 and $100 \mu \mathrm{M}$ celecoxib), AZACB cells were harvested and washed with PBS, resuspended in $70 \%$ ethanol in PBS, and frozen at $-30^{\circ} \mathrm{C}$ overnight. Before analysis, the cells were incubated for 15 min in propidium iodide (PI)/RNase Staining Buffer (BD Pharmingen, San Diego, CA, USA) in the dark. The suspension was then filtered into a 5-ml polystyrene round-bottomed tube with a cell-strainer cap and was analyzed using FACSCanto (both from Becton-Dickinson, Franklin Lakes, NJ, USA). Data analyses were performed using FlowJo 7 (Tree Star, Inc., Ashland, OR, USA). 
Table I. Real-time RT-PCR primer sequences.

\begin{tabular}{lll}
\hline Gene & \multicolumn{1}{c}{ Forward $\left(5^{\prime} \rightarrow 3^{\prime}\right)$} & Reverse $\left(5^{\prime} \rightarrow 3^{\prime}\right)$ \\
\hline$G A P D H$ & ATTCTATCCACGGCAAATCC & GGACTCCACAACATACTCAG \\
$p 21$ & CCTAATCTGCTCACCGGAAG & GGTGGCAAGCAGGGTATGTA \\
$p 27$ & CTCAGGCCAACTCAGAGGAC & TCTTAGGCGTCTGCTCCACT \\
$B c l-2$ & TGAACCGGCATCTGCACAC & GAGCAGCGCCTTCAGAGACA
\end{tabular}

RT-PCR, reverse transcription-polymerase chain reaction; GAPDH, glyceraldehyde-3-phosphate dehydrogenase.

Assessing changes in mitochondrial potential. Mitochondrial permeability and membrane depolarization were measured using a MitoPT ${ }^{\circledR}$ tetramethylrhodamine ethyl ester (TMRE) assay kit(ImmunoChemistry Technologies,LLC,Bloomington, MN, USA) according to the manufacturer's instructions. AZACB cells were seeded into 100-mm dishes (BD Falcon; Nippon Becton Dickinson) at a density of $3 \times 10^{5}$ cells/dish. After $24 \mathrm{~h}$ of treatment with selective COX-2 inhibitors, the cells were exposed to TMRE. The mitochondrial fluorescence intensity was measured using FACSCanto (488 nm excitation and $574 \mathrm{~nm}$ emission), and data were analyzed using FlowJo 7 (Tree Star, Inc.).

Annexin V/PI staining and flow cytometry. The different stages of apoptosis were analyzed using the ApoAlert ${ }^{\circledR}$ Annexin V-fluorescein isothiocyanate (FITC) Apoptosis kit (Clontech Laboratories, Mountain View, CA, USA) following the manufacturer's instructions. Both adherent and non-adherent cells were harvested using $0.25 \%$ of trypsin, and then centrifuged at 1,200 rpm for $5 \mathrm{~min}$. The cell pellets were then washed and resuspended in binding buffer, and then incubated with Annexin V-FITC and PI for $15 \mathrm{~min}$ in the dark at room temperature. The samples were analyzed using FACSCanto, and the data were analyzed using FlowJo 7.

Real-time reverse transcription-polymerase chain reaction $(R T-P C R)$. Total RNA was isolated from AZACB cells using TRIzol reagent (Life Technologies, Carlsbad, CA, USA), and was reverse transcribed to cDNA using PrimeScript ${ }^{\mathrm{TM}}$ RT kit (Takara Bio, Inc., Shiga, Japan) following the manufacturer's instructions as described previously (16,19-21). Real-time PCR was performed using SYBR Premix Ex Taq ${ }^{\mathrm{TM}}$ II (Takara Bio, Inc.), an ABI Prism 7500 Real-Time PCR system (Applied Biosystems, Inc., Foster City, CA, USA) and the following conditions: $95^{\circ} \mathrm{C}$ for $30 \mathrm{sec}$, and 40 cycles of $95^{\circ} \mathrm{C}$ for $5 \mathrm{sec}$ and $60^{\circ} \mathrm{C}$ for $34 \mathrm{sec}$. Glyceraldehyde-3-phosphate dehydrogenase $(G A P D H)$ expression was used as an internal control. The primer sequences used to amplify $p 21, p 27, B c l-2$, and $G A P D H$ are shown in Table I. The primers for $B c l-2$ were purchased from Takara Bio, Inc., and the other primers were obtained from Operon Biotechnology (Tokyo, Japan). All samples were amplified in triplicate in each experiment. The relative expression levels of mRNA were calculated using the comparative threshold cycle $(\mathrm{Ct})$ method.

Measuring caspase-3/7, -8 , and -9 activity. Caspase-3/7, -8, and -9 activity was analyzed using Caspase-Glo ${ }^{\circledR} 3 / 7,8$ and 9 assay kits (Promega Corp., Madison, WI, USA), respectively, following the manufacturer's instructions. Cells were cultured in white opaque tissue culture plates (BD Falcon; Nippon Becton Dickinson) at a density of $2.5 \times 10^{3}$ cells/well. Twenty-four hours after drug treatment (100 $\mu \mathrm{M}$ meloxicam and etodolac, or $10,25,40,50,75$, and $100 \mu \mathrm{M}$ celecoxib), the fluorescence was measured every $30 \mathrm{~min}$ for up to $180 \mathrm{~min}$ using the LB 960 Microplate Luminometer Centro (Berthold Japan K.K., Tokyo, Japan). All samples were measured in triplicate in each experiment.

Statistical analysis. Data are presented as means \pm SD. Statistical analyses were performed using the Bonferroni test or Mann-Whitney test to identify significant differences between the selective COX-2 inhibitor-treated cells and control cells. $\mathrm{P}<0.05$ was considered statistically significant.

\section{Results}

Celecoxib inhibits the proliferation of $A Z A C B$ cells. We reported previously that AZACB cells expressed lower levels of COX-2 protein than CF33 cells (18). In the current study, we confirmed that AZACB cells expressed the lowest levels of COX-2 among various canine mammary tumor cell lines, including CF33 and CF41.MG cells (Fig. 1A). Next, we assessed the effect of the selective COX-2 inhibitors meloxicam, etodolac, and celecoxib on cell viability to determine whether they inhibited the proliferation of AZACB cells. We measured cell proliferation using WST-8 assays $24 \mathrm{~h}$ after treatment with the selective COX-2 inhibitors. There was no difference in proliferation between the parent and control cells. As shown in Fig. 1D, 75 and $100 \mu \mathrm{M}$ celecoxib significantly induced growth arrest $24 \mathrm{~h}$ after treatment compared with control cells; however, meloxicam and etodolac had no significant effect (Fig. 1B and C). These results suggest that celecoxib markedly inhibited the proliferation of AZACB cells.

Celecoxib inhibits the proliferation of AZACB cells mainly via $C O X$-2-independent mechanisms. Numerous reports have suggested that NSAIDs exert antitumor effects on human cancer cells via COX-2-independent mechanisms (24). Next, we evaluated whether celecoxib inhibited cell proliferation in a COX-2-dependent or -independent manner by examining the effect of DMC on the proliferation of canine mammary tumor cells. DMC is a structural isomer of celecoxib that lacks COX-2-inhibitory activity (25). As shown in Fig. 2A, DMC 

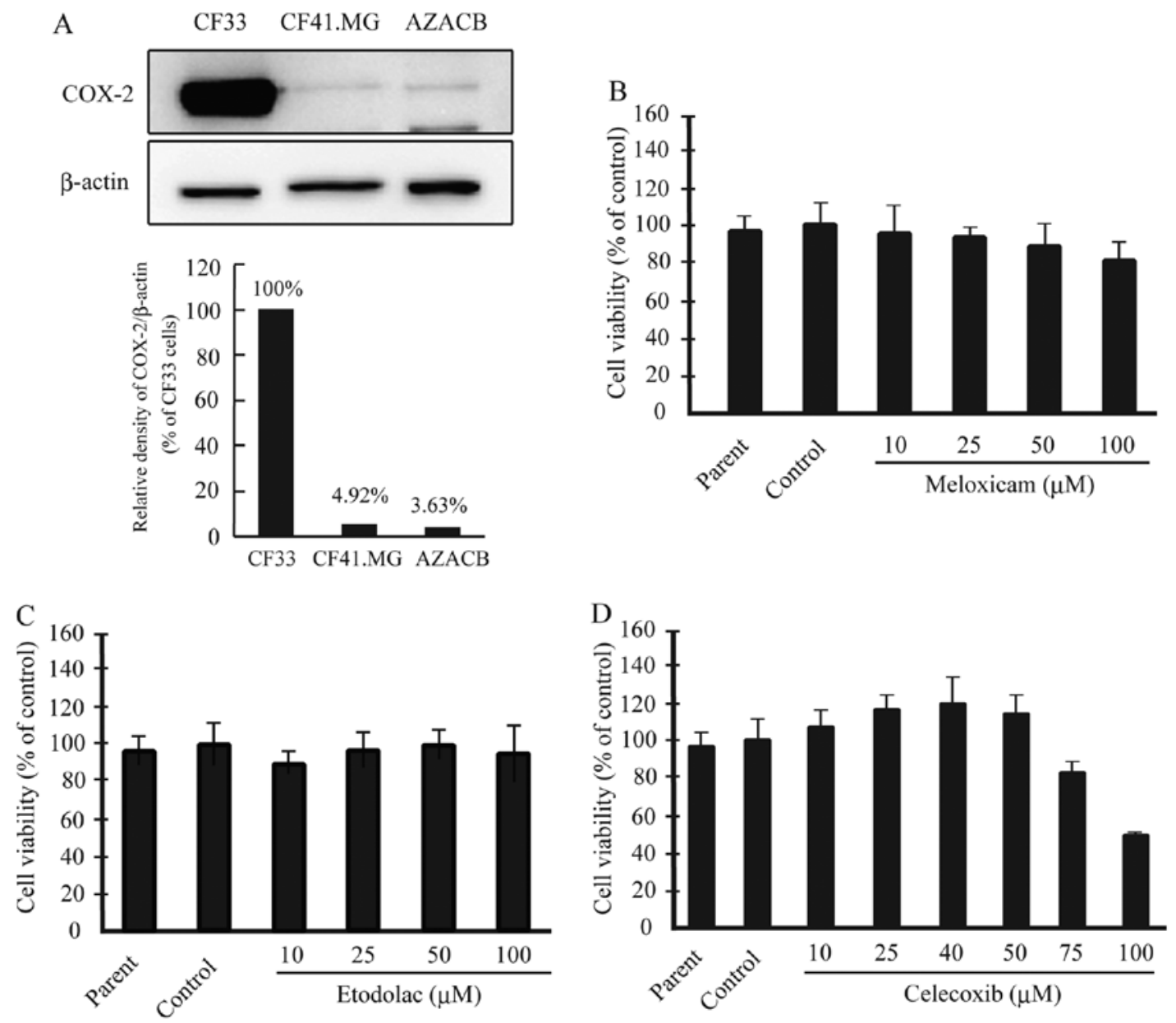

Figure 1. Celecoxib inhibits the proliferation of AZACB cells. (A) Western blotting to assess the levels of cyclooxygenase-2 (COX-2) in CF33, CF41.MG, and AZACB cells. (B-D) The effects of selective COX-2 inhibitors on cell proliferation were analyzed using WST- 8 assays $24 \mathrm{~h}$ after treatment. Data are presented as means $\pm \mathrm{SD}(\mathrm{n}=5)$. The viability of AZACB cells treated with (B) meloxicam, (C) etodolac and (D) celecoxib. Control cells were treated with $0.1 \%$ DMSO, and parent cells were untreated.
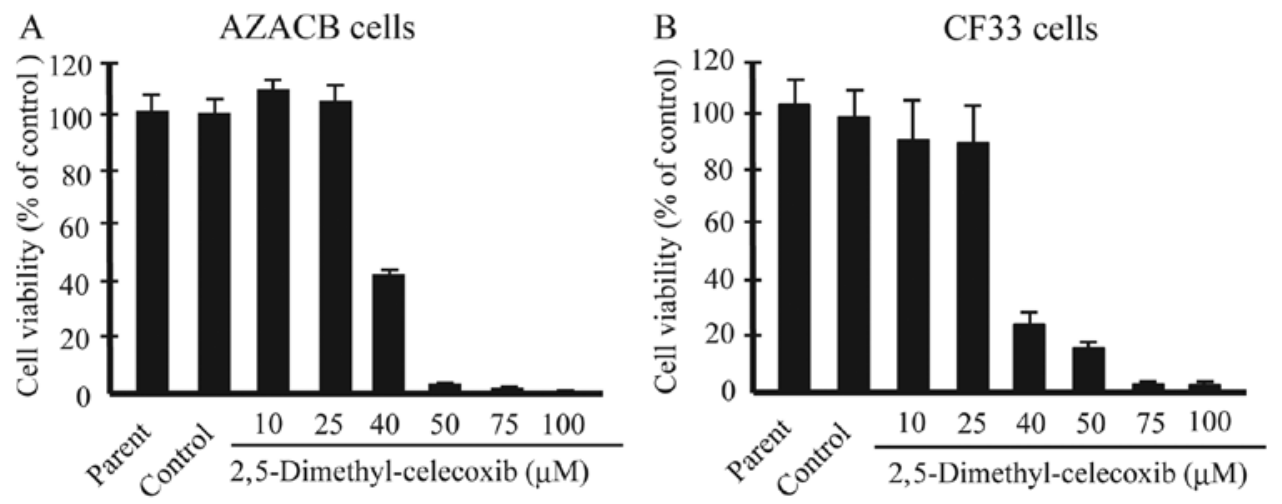

Figure 2. Celecoxib inhibits the proliferation of AZACB cells via cyclooxygenase-2 (COX-2)-independent mechanisms. (A and B) The effects of 2,5-dimethyl-celecoxib (DMC) on cell proliferation were analyzed using WST-8 assays $24 \mathrm{~h}$ after treatment. The data are presented as means \pm SD ( $\mathrm{n}=5$ ).

inhibited the proliferation of AZACB and CF33 cells, which express low and high levels of COX-2, respectively (Fig. 2B). This suggests that celecoxib inhibited the proliferation of canine mammary tumor cells via COX-2-independent mechanisms.

We demonstrated previously that celecoxib downregulated the expression of COX-2 in CF33 cells (16). As shown in Fig. 3A and B, COX-2 protein expression was reduced only in AZACB cells treated with $100 \mu \mathrm{M}$ celecoxib. It is well known that COX-2 catalyzes the production of PGs such as $\mathrm{PGE}_{2}$. However, despite the reduced expression of COX-2, no significant changes in $\mathrm{PGE}_{2}$ production were observed in celecoxib-treated AZACB cells compared with control cells (Fig. 3C). These results suggest that celecoxib-induced growth inhibition in AZACB cells is mediated mainly 
A

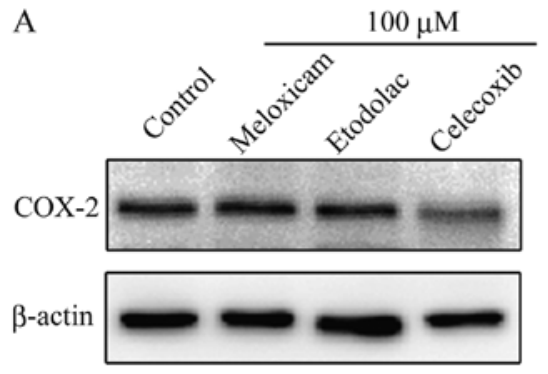

B

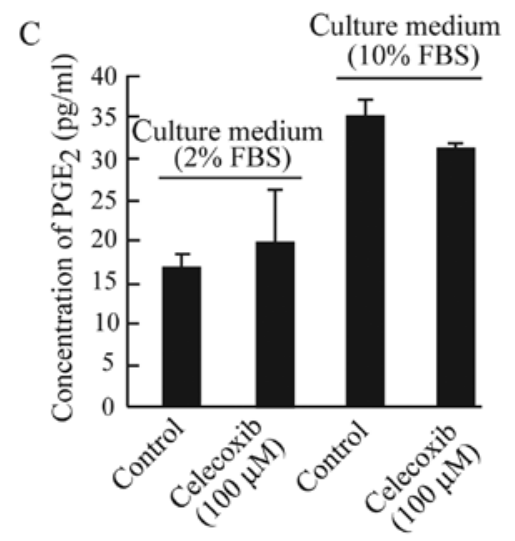

Figure 3. Celecoxib downregulates cyclooxygenase-2 (COX-2) expression without affecting prostaglandin $\mathrm{E}_{2}\left(\mathrm{PGE}_{2}\right)$ levels in AZACB cells. (A) Western blotting of COX-2 levels in AZACB cells treated with selective COX-2 inhibitors for $24 \mathrm{~h}$. (B) Western blotting of COX-2 levels in AZACB cells treated with the indicated doses of celecoxib. (C) Enzyme immunoassay for $\mathrm{PGE}_{2}$ secretion into culture medium containing 2 or 10\% fetal bovine serum (FBS) in AZACB cells treated with celecoxib for $24 \mathrm{~h}$. The experiment was performed in triplicate, and the data are presented as means \pm SD.
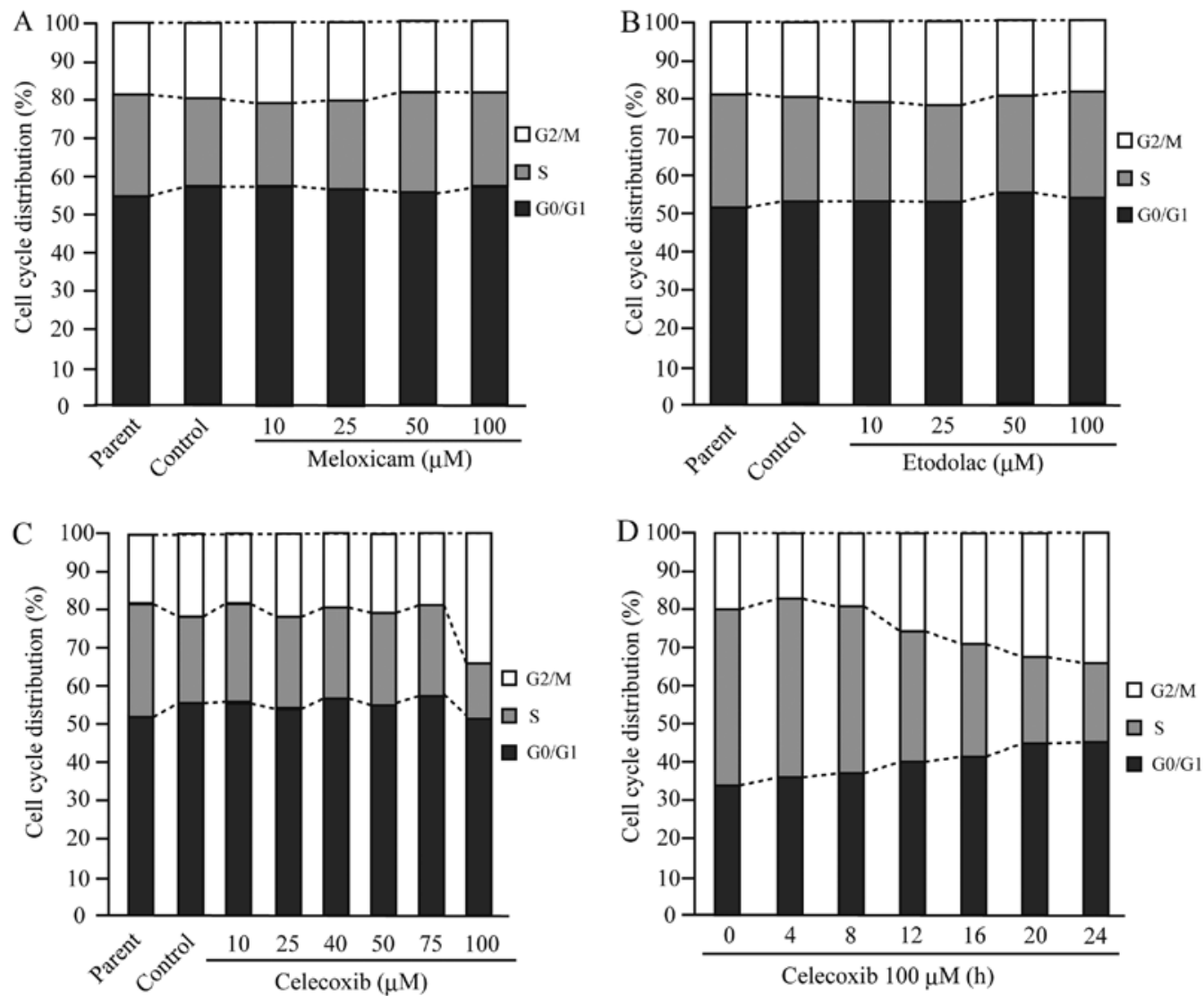

Figure 4. Celecoxib decreases the number of cells in $\mathrm{S}$ phase and increases the number of those in G2/M arrest. (A-D) The effects of selective cyclooxygenase-2 (COX-2) inhibitors on the distribution of cells in the cycle stage were analyzed using flow cytometry of propidium iodide (PI)-stained cells. (A-C) The percentage of cells treated with 10-100 $\mu \mathrm{M}$ meloxicam, etodolac and celecoxib, respectively, distributed in G0/G1, S, and G2/M phases of the cell cycle. (D) The distribution of AZACB cells in each stage of the cell cycle after treatment with $100 \mu \mathrm{M}$ celecoxib for the indicated times. Control cells were treated with $0.1 \%$ DMSO, and parent cells were not treated. A total of 20,000 cells were analyzed in each experiment. 

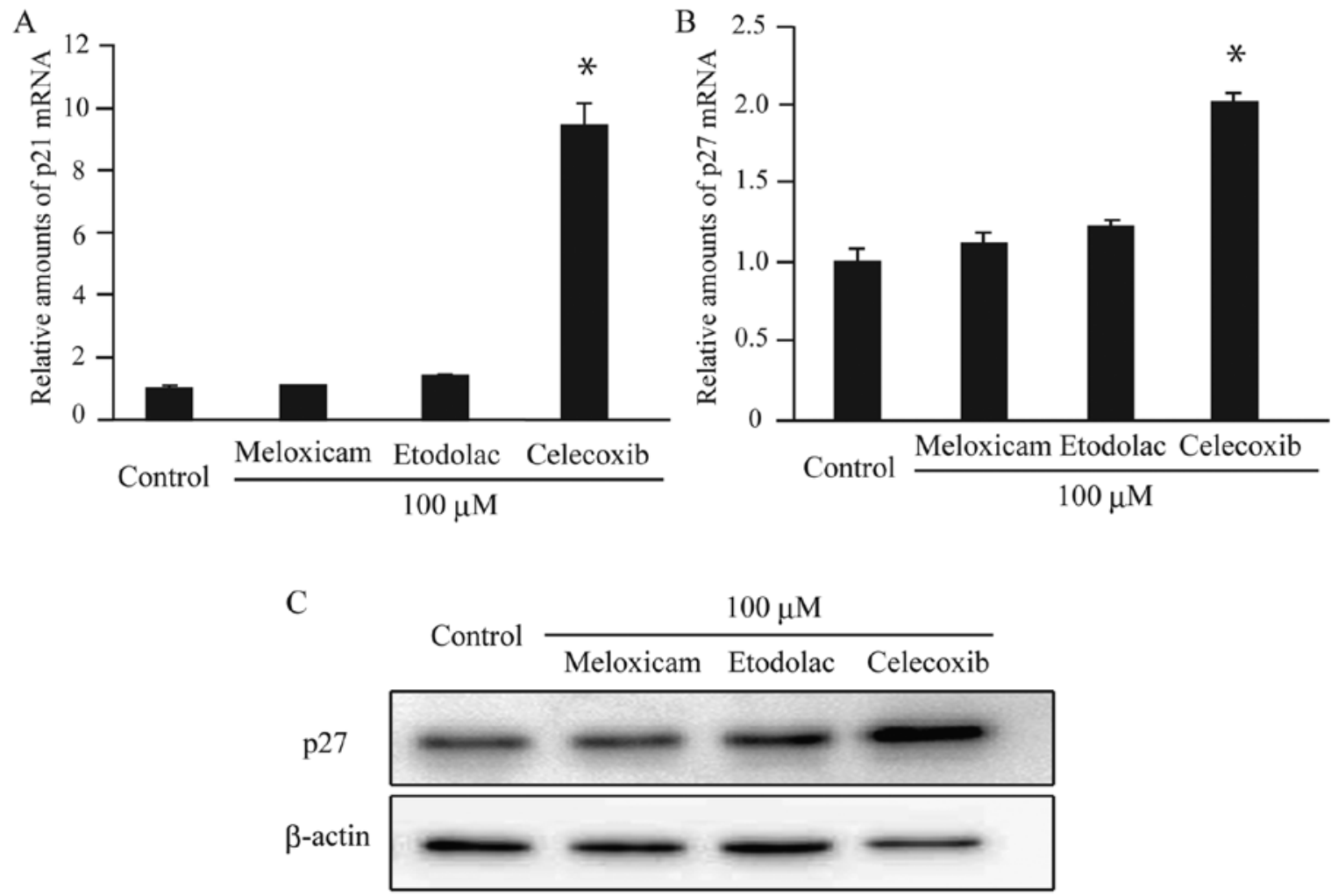

Figure 5. Celecoxib increases the levels of the cyclin-dependent kinase inhibitors (CDKIs) $p 21$ and $p 27$ in AZACB cells. (A-B) Real-time reverse transcription-polymerase chain reaction (RT-PCR) analysis of $p 21$ and $p 27$ mRNA levels in AZACB cells treated with selective cyclooxygenase-2 (COX-2) inhibitors. The data are presented as means $\pm \mathrm{SD}(\mathrm{n}=3)$. " $\mathrm{P}<0.01$ compared with control cells. (C) Western blotting shows the expression of p27 protein in AZACB cells treated with selective COX-2 inhibitors.

by COX-2-independent mechanisms. Furthermore, the unchanged $\mathrm{PGE}_{2}$ secretion after celecoxib treatment might be caused by low levels of COX-2 expression compared with other canine mammary tumor cells. These results suggest that celecoxib might affect the expression and/or activation of proteins such as NF- $\mathrm{KB}$, which regulates $\mathrm{COX}-2$ expression $(24,26-29)$.

Celecoxib decreased the number of cells in $S$ phase and increased G2/M arrest by upregulating p21 and p27. We demonstrated previously that celecoxib treatment reduced the number of CF33 cells in S phase and increased those in G0/G1 (18). In addition, meloxicam and etodolac slightly induced G0/G1 arrest (18). As shown in Fig. 4A and B, there was no significant change in the cell cycle distribution patterns in AZACB cells treated with etodolac and meloxicam. However, treatment with $100 \mu \mathrm{M}$ celecoxib markedly induced $\mathrm{G} 2 / \mathrm{M}$ arrest and decreased the number of cells in $\mathrm{S}$ phase (Fig. 4C). Furthermore, this effect occurred after $12 \mathrm{~h}$ of treatment (Fig. 4D). To confirm that celecoxib induced cell cycle arrest at the G2/M phase, we next evaluated the expression of the cyclin-dependent kinase inhibitors (CDKIs) $p 21$ and $p 27$. There were no changes in the expression of $p 21$ and $p 27$ in meloxicam- or etodolac-treated cells (Fig. 5A-C). In contrast, treatment with celecoxib increased the levels of both $p 21$ and p27 in AZACB cells (Fig. 5A-C). Therefore, these data suggest that celecoxib induced $\mathrm{G} 2 / \mathrm{M}$ arrest and reduced the number of AZACB cells in S phase by increasing the expression of CDKIs, including $p 21$ and $p 27$.
Treatment with $100 \mu M$ celecoxib markedly induced AZACB cell apoptosis. We recently reported that celecoxib markedly inhibited the proliferation of CF33 canine mammary tumor cells by inducing apoptosis (18). Therefore, we next assessed the effects of meloxicam, etodolac, and celecoxib on apoptosis in AZACB cells. As shown in Fig. 6A and B, there were no changes in apoptosis in meloxicam- or etodolac-treated AZACB cells. However, as expected, treating cells with $100 \mu \mathrm{M}$ celecoxib induced apoptosis (Fig. 6C); these effects were time-dependent (Fig. 6D). To confirm these observations, we next analyzed apoptosis using Annexin V/PI double staining. Data revealed that treatment with $100 \mu \mathrm{M}$ celecoxib for $24 \mathrm{~h}$ induced both early and late apoptosis (Fig. 6E and F). As expected, treating AZACB cells with $100 \mu \mathrm{M}$ meloxicam or etodolac had no effect on either early or late apoptosis (Fig. 6E and F).

The imbalance between pro-apoptotic (Bax, Bim, and Bak) and anti-apoptotic proteins (Bcl-2 and Bcl-xL) leads to apoptosis by stimulating mitochondrial outer membrane permeabilization (MOMP) (30). Accordingly, we assessed changes in the expression of apoptotic proteins in celecoxib-treated AZACB cells. Celecoxib-treated AZACB cells exhibited elevated Bax and Bim expression, and reduced Bcl-2 expression (Fig. 7A-D). However, levels of Bax were only slightly elevated in celecoxib-treated AZACB cells (Fig. 7A and C). These changes were induced by treatment with $\geq 75 \mu \mathrm{M}$ celecoxib (Fig. 7C and D). It is known that MOMP leads to a decrease in mitochondrial membrane potential (31). Therefore, we analyzed changes in mitochondrial membrane 

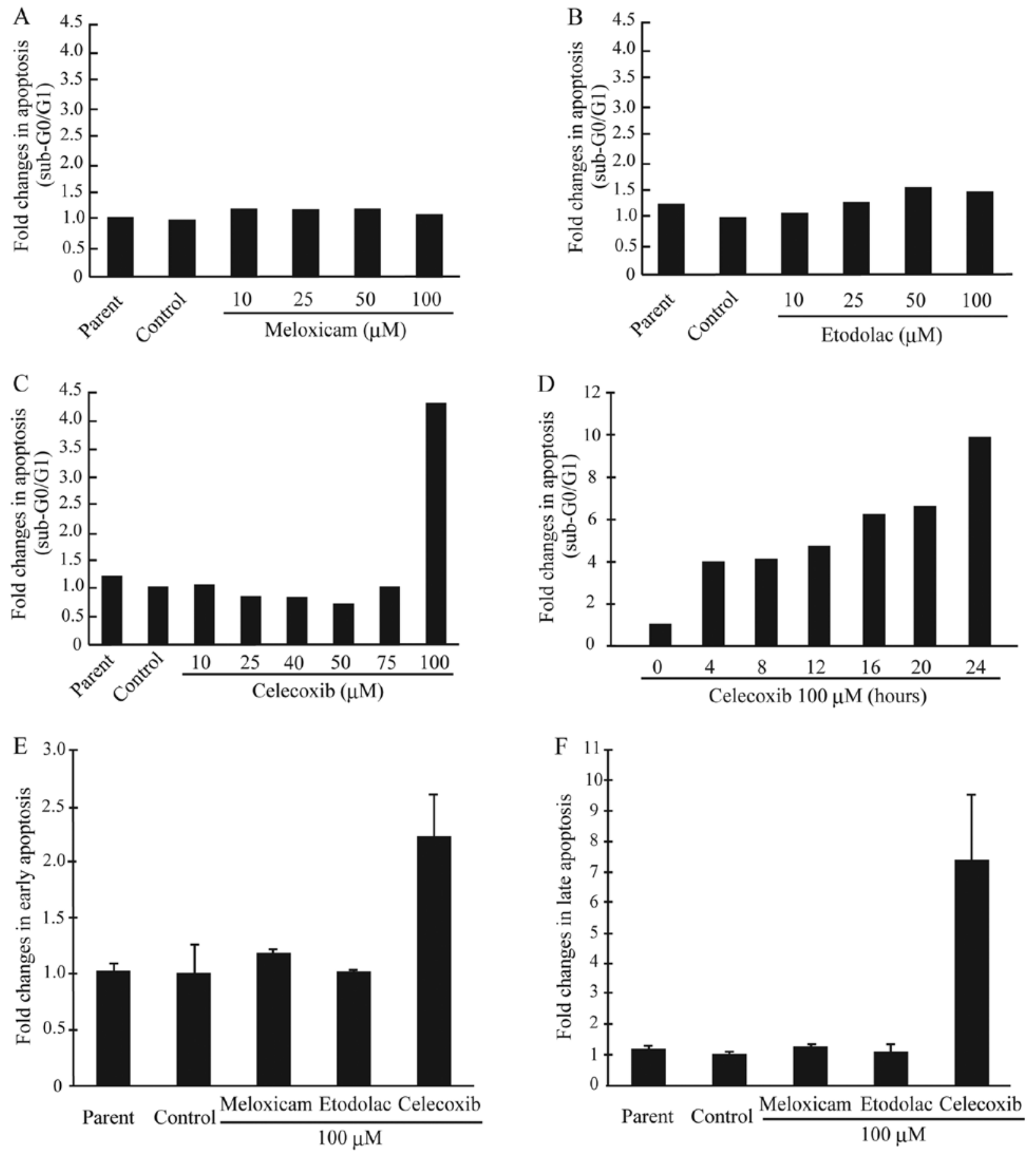

Figure 6. Treatment with $100 \mu \mathrm{M}$ celecoxib induces apoptosis in AZACB cells. (A-C) The apoptosis induced by selective cyclooxygenase-2 (COX-2) inhibitors was analyzed by assessing propidium iodide (PI)-stained cells by FACS analysis. The data show the cells in the sub-G0/G1 peak $24 \mathrm{~h}$ after treatment with 0-100 $\mu \mathrm{M}$ of the selective COX-2 inhibitors meloxicam, etodolac, and celecoxib, respectively, for $24 \mathrm{~h}$. (D) The sub-G0/G1 peak of AZACB cells treated with $100 \mu \mathrm{M}$ celecoxib for the indicated times. (E-F) The apoptotic effects of $100 \mu \mathrm{M}$ celecoxib in AZACB cells were confirmed using flow cytometry to analyze Annexin V-fluorescein isothiocyanate (FITC) and PI double-stained cells. The data are presented as means \pm SD. (E) The number of early apoptotic cells (Annexin V-positive, PI-negative). (F) The number of late apoptotic cells (Annexin V-positive, PI-positive). Control cells were treated with $0.1 \%$ DMSO, and parent cells were not treated. A total of 20,000 cells were analyzed in each experiment.

potential using flow cytometric analysis of TMRE-stained cells to directly measure whether celecoxib induced MOMP. Our results showed that treating cells with $100 \mu \mathrm{M}$ celecoxib, but not meloxicam and etodolac, decreased mitochondrial membrane potential (Fig. 7E). Moreover, the decrease in mitochondrial membrane potential was observed only in AZACB cells treated with $100 \mu \mathrm{M}$ celecoxib, and not lower doses (Fig. 7F). These findings confirm that celecoxib induces apoptosis in AZACB cells, which express low levels of COX-2 .

Celecoxib induces apoptosis in AZACB cells by activating both the intrinsic and extrinsic apoptotic pathways. To further clarify the effect of selective COX-2 inhibitors on apoptosis, we analyzed the caspase-3/7 activity. Only celecoxib induced 
A
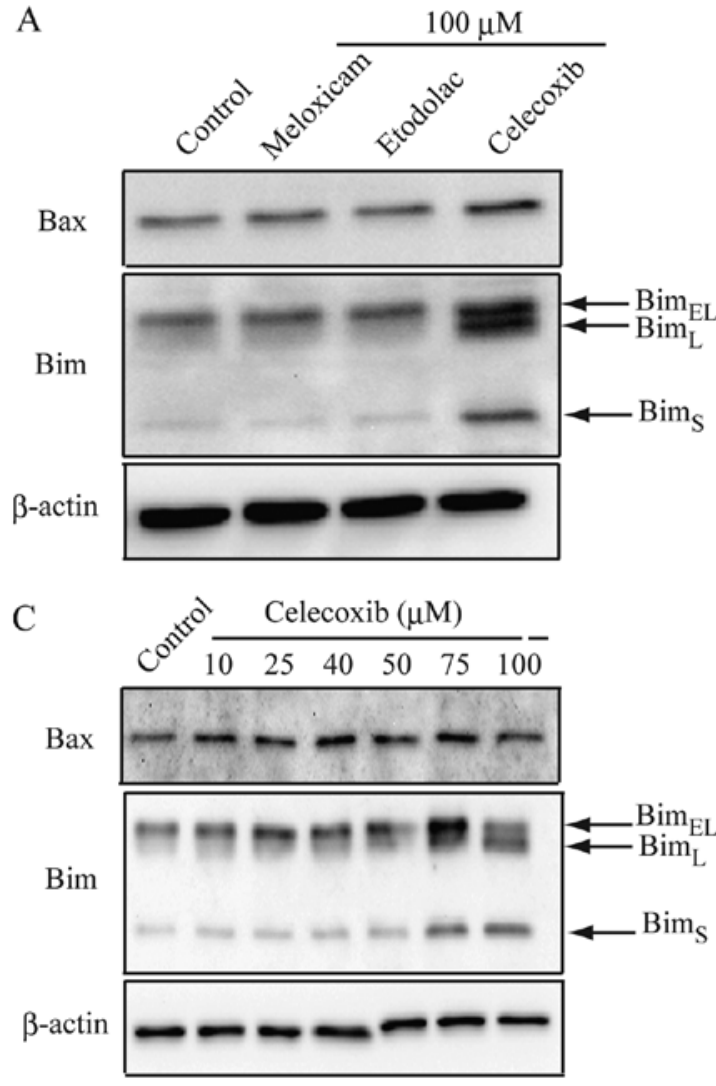

E

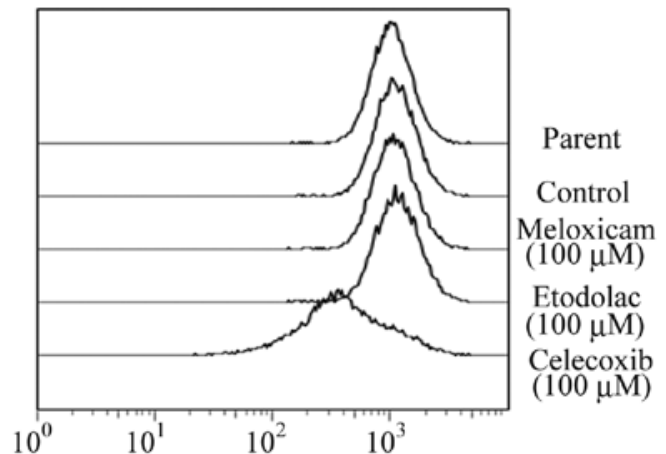

B

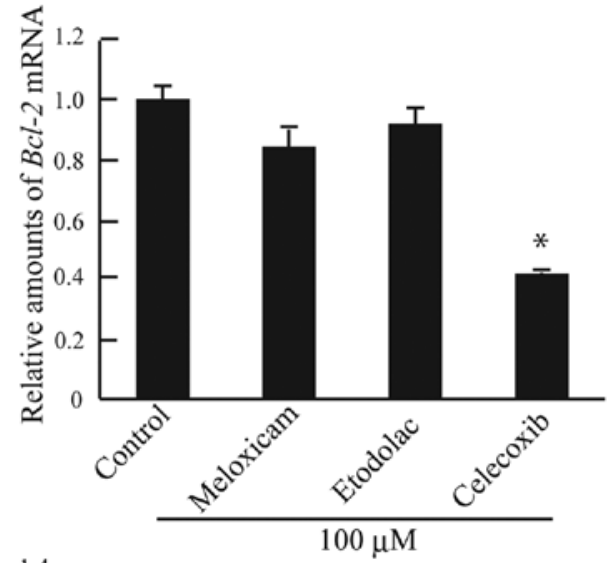

$\mathrm{D}$
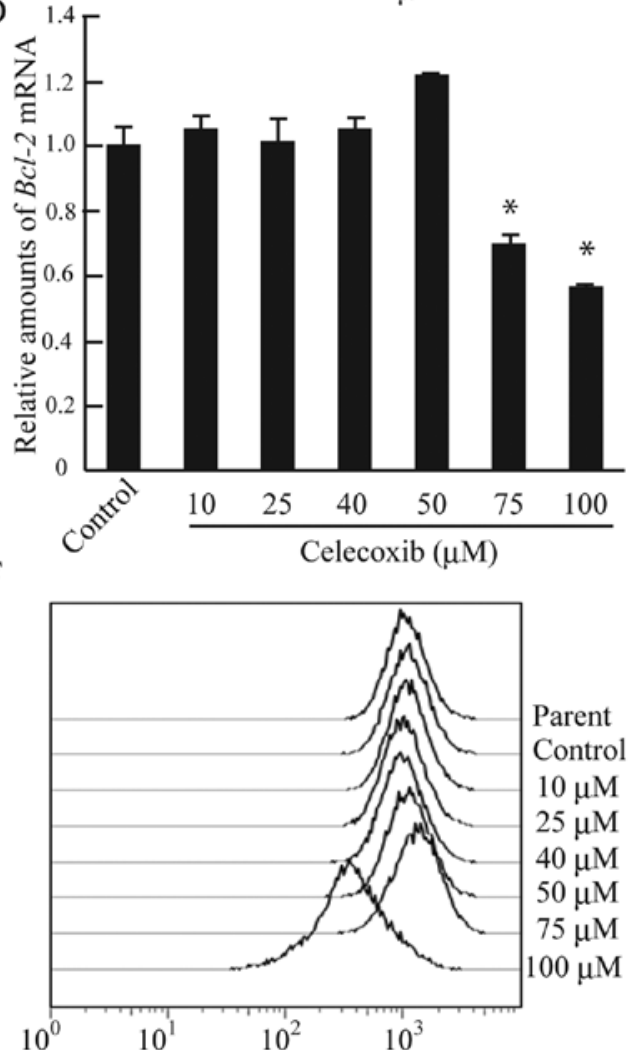

Figure 7. Celecoxib alters the expression of $B c l-2$ family members, which decreased mitochondrial membrane potential. (A) Western blotting of the expression of the pro-apoptotic proteins Bax and Bim in AZACB cells treated with selective cyclooxygenase-2 (COX-2) inhibitors for $24 \mathrm{~h}$. (B) Real-time reverse transcription-polymerase chain reaction (RT-PCR) analysis of $B c l-2$ mRNA levels in AZACB cells treated with selective COX-2 inhibitors. The data are presented as means $\pm \mathrm{SD}(\mathrm{n}=3) .{ }^{*} \mathrm{P}<0.01$ compared with control cells. (C) Western blotting of the expression of the pro-apoptotic proteins Bax and Bim in AZACB cells treated with the indicated doses of celecoxib. (D) Real-time RT-PCR analysis of Bcl-2 mRNA levels in AZACB cells treated with the indicated doses of celecoxib. The data are presented as means $\pm \mathrm{SD}(\mathrm{n}=3)$. ${ }^{*} \mathrm{P}<0.01$ compared with control cells. (E-F) The altered mitochondrial membrane depolarization caused by selective COX-2 inhibitors was confirmed by analyzing tetramethylrhodamine ethyl ester (TMRE)-stained cells using flow cytometry. A total of 20,000 cells were analyzed in each experiment. The control cells were treated with $0.1 \%$ DMSO, and the parent cells were not treated.

the activation of caspase-3/7 (Fig. 8A), and this effect required treatment with a dose of $100 \mu \mathrm{M}$ celecoxib (Fig. 8B). Caspase-dependent apoptosis is divided into the intrinsic and extrinsic pathways, which are induced by the activation of initiator caspase-8 or -9 , respectively (32-34). The subsequent activation of the effector caspase- 3 and -7 then leads to apoptosis (35). To determine whether celecoxib induced apoptosis via the intrinsic or extrinsic apoptotic pathway, we measured the activity of caspase- 8 and -9 in AZACB cells treated with selective COX-2 inhibitors. As shown in Fig. 8C and D, celecoxib induced the activation of both caspase- 8 and -9 in AZACB cells. Celecoxib also induced the cleavage of
Bid to truncated Bid (Fig. 8E). These data suggest that celecoxib-induced apoptosis is mediated by both the intrinsic and extrinsic apoptotic pathways.

To confirm the activation of these apoptotic pathways in celecoxib-treated cells, we next assessed the effect of caspase- 8 and -9 inhibitors on celecoxib-induced apoptosis in AZACB cells. The caspase-8 inhibitor Z-IETD-FMK completely inhibited celecoxib-induced caspase- 8 activation (Fig. 9A). However, it did not completely block celecoxib-induced apoptosis (Fig. 9C). Similarly, the caspase-9 inhibitor Z-LEHD-FMK significantly inhibited celecoxib-induced caspase-9 activation in AZACB cells (Fig. 9B). 

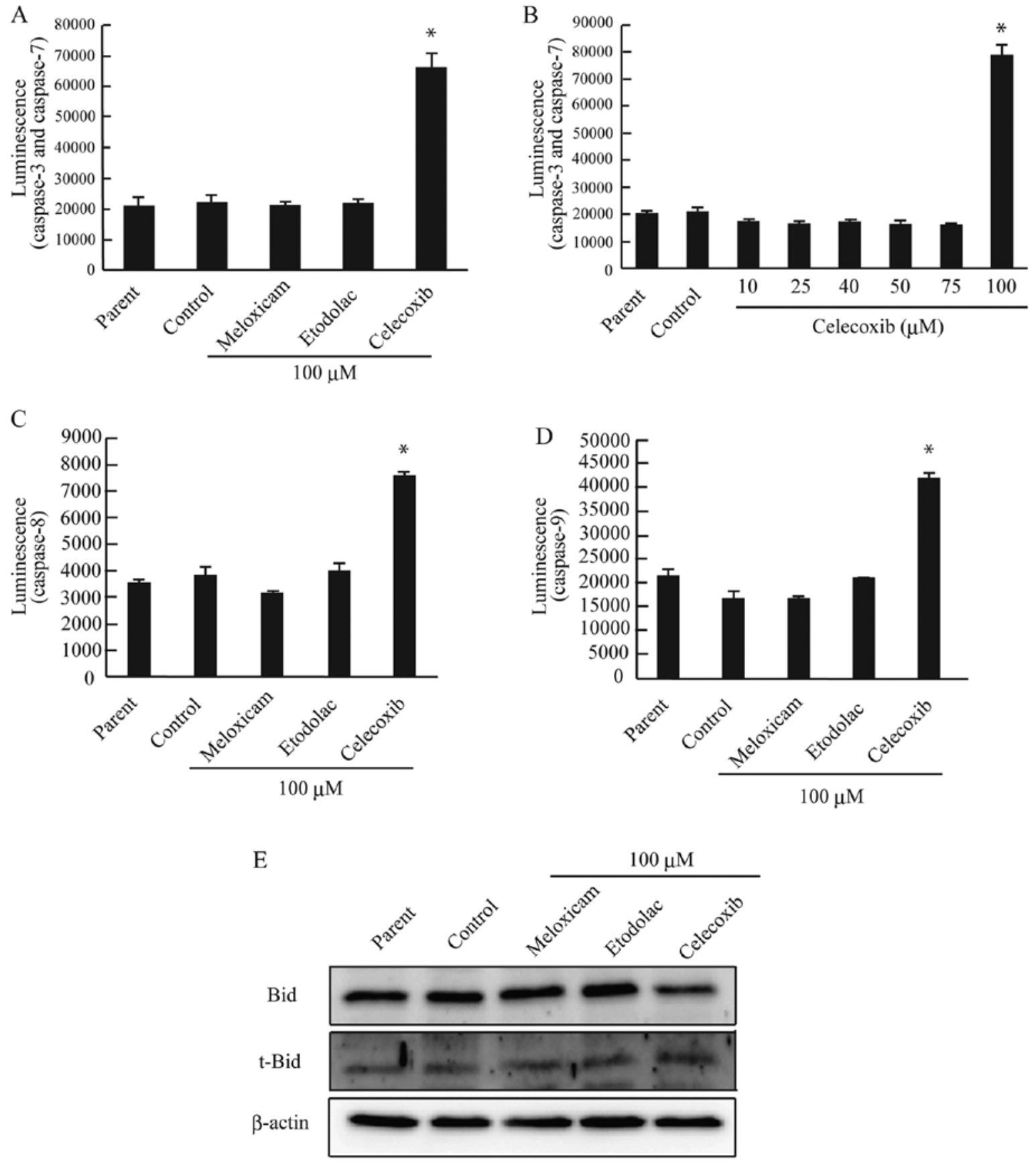

Figure 8. Celecoxib activates both caspase- 8 and -9 , which subsequently induced apoptosis by increasing caspase-3/7 activity in AZACB cells. (A) Caspase-3/7 activity after treatment with $100 \mu \mathrm{M}$ meloxicam, etodolac, and celecoxib for $24 \mathrm{~h}$ was measured using Caspase-Glo ${ }^{\circledast 3} 3 / 7$ assays. (B) Caspase-3/7 activity after treatment with the indicated doses of celecoxib for $24 \mathrm{~h}$. (C) Caspase- 8 activity after treatment with $100 \mu \mathrm{M}$ meloxicam, etodolac, and celecoxib for $24 \mathrm{~h}$ was measured using Caspase-Glo 8 assays. (D) Caspase-9 activity after treatment with $100 \mu \mathrm{M}$ meloxicam, etodolac, and celecoxib for $24 \mathrm{~h}$ was measured using Caspase-Glo ${ }^{\circledast} 9$ assays. (E) Celecoxib induced the cleavage of Bid to truncated Bid. The control cells were treated with $0.1 \%$ DMSO, and the parent cells were not treated. The data are presented as means $\pm \mathrm{SD}(\mathrm{n}=3) .{ }^{*} \mathrm{P}<0.01$ compared with control cells.

However, it did not completely inhibit celecoxib-induced apoptosis (Fig. 9D). These results strongly support the notion that celecoxib-induced apoptosis is mediated by both the intrinsic and extrinsic apoptotic pathways in AZACB cells.

\section{Discussion}

In humans, the regular intake of NSAIDs such as aspirin and selective COX-2 inhibitors is associated with a decreased risk of cancer incidence, distant recurrence, and cancer-related deaths in various cancers, including breast and colon cancers $(36,37)$. However, it largely remains unclear whether NSAIDs might be useful chemotherapy or chemopreventative agents in canine mammary tumors. Our findings revealed that celecoxib inhibited cell proliferation by decreasing the number of cells in S phase and increasing $\mathrm{G} 2 / \mathrm{M}$ arrest by stimulating the expression of the CDKIs p21 and p27 in AZACB cells. Furthermore, our findings suggest that celecoxib might exert antitumor effects mainly via COX-2-independent mechanisms in canine mammary tumor cells. In addition, celecoxib might 

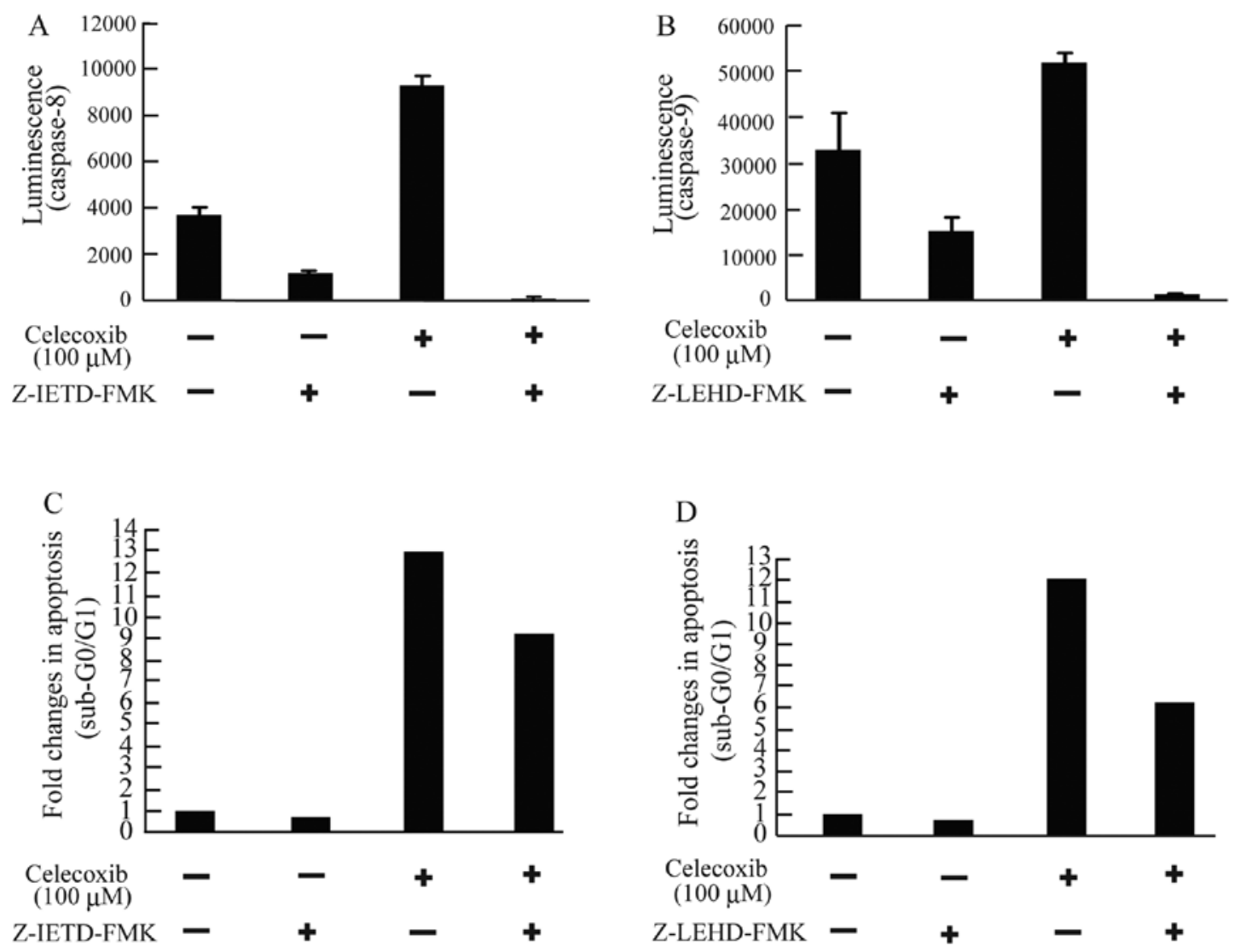

Figure 9. Celecoxib induces apoptosis via both the intrinsic and extrinsic apoptotic pathways in AZACB cells. (A-B) To confirm the inhibitory effects of caspase-8 (Z-IETD-FMK) and caspase-9 (Z-LEHD-FMK) on caspase-8 and -9 activities, we analyzed the respective caspase activities using Caspase-Glo ${ }^{\circledast} 8$ and 9 assays, respectively. Cells were treated with each inhibitor at a final concentration of $20 \mu \mathrm{M}$. Control cells were treated with DMSO only. The data are presented as means $\pm \mathrm{SD}(\mathrm{n}=3)$. (C-D) To evaluate whether celecoxib-induced apoptosis was dependent on the intrinsic or extrinsic apoptotic pathway, AZACB cells treated with caspase inhibitors and/or celecoxib for $24 \mathrm{~h}$ were analyzed using FACS analysis. A total of 20,000 cells were analyzed in each experiment. Control cells were only treated with DMSO. Cells were treated with each inhibitor at a final concentration of $20 \mu \mathrm{M}$.

induce apoptosis by activating both the intrinsic and extrinsic apoptotic pathways in AZACB cells. We demonstrate, for the first time, that celecoxib shows potential be a useful chemotherapy agent in canine mammary tumor cells, regardless of COX-2 expression levels.

Several studies have reported that the aberrant overexpression of COX-2 is observed in human cancers such as breast cancer, prostate cancer, lung cancer, and colorectal adenomas and carcinomas (38). In addition, elevated COX-2 levels were associated with unfavorable outcome, lymph node metastasis, and distant metastasis (39-41). Therefore, various studies have suggested that selective COX-2 inhibitors might be useful chemopreventative and chemotherapeutic agents in human breast cancer. Similar to human breast cancer, some reports have identified correlations between COX-2 expression and angiogenesis, poor prognosis, and the development of distant metastases in canine mammary tumors $(17,42,43)$. Consistent with this, we demonstrated previously that selective COX-2 inhibitors, particularly celecoxib, had powerful antitumor activity in CF33 cells that was mediated by the induction of apoptosis (18). Furthermore, the current study suggests that celecoxib exhibited antitumor effects in canine mammary tumor cells regardless of COX-2 expression. These results strongly support the hypothesis that celecoxib might be a useful chemotherapeutic agent in canine mammary tumor cells. Furthermore, celecoxib might be a potent adjunctive therapeutic agent for intractable canine mammary tumors.

Apoptosis (programmed cell death), plays a key role in the development and regulation of tissue homeostasis. Apoptosis can be triggered by at least two major pathways: the intrinsic (mitochondrial) and the extrinsic (death-receptor) pathway. In the extrinsic pathway, caspase- 8 is activated after the interaction of death receptors, including CD95, tumor necrosis factor-related apoptosis-inducing ligand (TRAIL)-R1 and -R2, as well as TNF-receptor-1, with their cognate ligands CD95, TRAIL, and TNF, respectively $(32,34)$. In contrast, in the intrinsic pathway, caspase- 9 is activated by MOMP followed by an imbalance between pro- and anti-apoptotic proteins (30,32-34). These distinct pathways then converge to activate the effector caspase-3 and -7 (30). However, it remains controversial whether celecoxib-induced apoptosis is mediated by the intrinsic or extrinsic pathway. Celecoxib-induced apoptosis occurred via the intrinsic pathway and a Bak-dependent, Bcl-2-independent pathway in Jurkat T-lymphoma cells $(44,45)$. In contrast, Liu et al reported that celecoxib-induced apoptosis in human non-small cell lung cancer cell lines was mediated by activation of the extrinsic pathway following increased TRAIL-R2 expression, enhanced TRAIL-induced apoptosis, and the downregula- 
tion of cellular FADD-like interleukin-1 $\beta$-converting enzyme-inhibitory protein $(46,47)$.

The current study suggests that celecoxib activated both the intrinsic and extrinsic pathways in AZACB cells, which was mediated by the activation of the initiator caspase- 8 and -9 . In the intrinsic pathway, our data suggest that an imbalance between pro-apoptotic (Bax and Bim) and anti-apoptotic (Bcl-2) proteins leads to breakdown of mitochondrial membrane potential, which sequentially activates caspase- 9 and $-3 / 7$. In the extrinsic pathway, celecoxib activates caspase- $3 / 7$ via -8 in AZACB cells. Interestingly, Bid plays a key role in crosstalk between the intrinsic and extrinsic apoptotic pathways (34). Therefore, the findings of the current study support the notion that the cleavage of Bid by active caspase- 8 might induce mitochondrial depolarization in celecoxib-treated AZACB cells. In addition, specific inhibitors of caspase- 8 and -9 could not completely block celecoxib-induced apoptosis in AZACB cells. The present study showed, for the first time, that activation of both the intrinsic and extrinsic apoptotic pathways play a critical role in celecoxib-induced apoptosis in canine mammary tumors. A recent study reported that Bim, a pro-apoptotic Bcl-2 homology domain 3-only protein, is a critical mediator of anoikis in MCF10A cells (48). The current study demonstrated that a high dose of celecoxib significantly upregulated Bim protein expression in AZACB cells. These results suggest that celecoxib induced anoikis in AZACB cells.

The interaction of COX-2-derived PGs (e.g., $\mathrm{PGE}_{2}$ ) with their receptors (e.g., EP1, 2, 3, and 4) induces apoptosis resistance, cell proliferation, angiogenesis, invasion, and metastasis (49-54). However, it was revealed previously that NSAIDs exert antitumor activities in cancer cells via both COX-2-dependent and -independent mechanisms (41). For COX-2-independent mechanisms, it was proposed that NSAIDs affect gene expression patterns or the activation of various molecules such as $\mathrm{NF}-\kappa \mathrm{B}$, pyruvate dehydrogenase lipoamide kinase isozyme 1 (PDK1)/Akt, p21, and peroxisome proliferator-activated receptors (24). In particular, $\mathrm{NF}-\kappa \mathrm{B}$ plays a critical role in cell survival and regulates the expression of various genes in cancer cells. $\mathrm{NF}-\kappa \mathrm{B}$ is generally localized in the cytoplasm in its inactive form bound to its inhibitor protein I $\mathrm{B} \alpha$. The phosphorylation and subsequent proteasomal degradation of I $\kappa \mathrm{B} \alpha$ leads to the nuclear translocation of NF- $\mathrm{B}$ (55). Furthermore, COX-2 expression is regulated by $N F-\kappa B$ in various cells (26-29). Therefore, it is possible that $\mathrm{NF}-\kappa \mathrm{B}$ might be a key molecule in both the celecoxib-induced downregulation of COX-2 and COX-2-independent antitumor effects in canine mammary tumor cells. Our data also demonstrated that celecoxib enhanced the expression of both p21 and p27. Therefore, our observations suggest that both p21 and p27 might play critical roles in celecoxib-induced COX-2-independent antitumor mechanisms in canine mammary tumors.

Recently, Seo et al reported that celecoxib exerted antitumor effects in both COX-2-expressing and -non-expressing canine melanoma cells (56). Consistent with this, the current study demonstrated that a high dose of celecoxib induced growth arrest and apoptosis in canine mammary tumor cells, regardless of COX-2 expression. Taken together, these data suggest that celecoxib might act via both COX-2-dependent and -independent mechanisms in various canine cancers. Accordingly, selective COX-2 inhibitors might cause more favorable therapeutic responses in various canine cancers compared with human or other cancers.

In conclusion, our findings support the hypothesis that celecoxib might be a viable chemotherapy or chemopreventative agent in canine mammary tumors, regardless of COX-2 expression. In particular, celecoxib exerts antitumor activity via COX-2-independent mechanisms in canine mammary tumors. In the future, it might be possible to use a combination of celecoxib and other antitumor drugs to treat canine mammary tumors, regardless of their COX-2 expression status.

\section{Acknowledgements}

We thank Ms. Mitsune Suzuki and Ms. Aiko Sato (Nihon University, Kanagawa, Japan) for help in performing the experiments. This study was supported in part by a Grant-in-Aid from Nihon University (to T. Saito).

\section{References}

1. Hawkey CJ: COX-2 inhibitors. Lancet 353: 307-314, 1999.

2. Chandrasekharan NV, Dai H, Roos KL, Evanson NK, Tomsik J, Elton TS and Simmons DL: COX-3, a cyclooxygenase-1 variant inhibited by acetaminophen and other analgesic/antipyretic drugs: cloning, structure, and expression. Proc Natl Acad Sci USA 99: 13926-13931, 2002.

3. Tsujii M and DuBois RN: Alterations in cellular adhesion and apoptosis in epithelial cells overexpressing prostaglandin endoperoxide synthase 2. Cell 83: 493-501, 1995.

4. Tsujii M, Kawano $\mathrm{S}$ and DuBois RN: Cyclooxygenase-2 expression in human colon cancer cells increases metastatic potential. Proc Natl Acad Sci USA 94: 3336-3340, 1997.

5. Tsujii M, Kawano S, Tsuji S, Sawaoka H, Hori M and DuBois RN: Cyclooxygenase regulates angiogenesis induced by colon cancer cells. Cell 93: 705-716, 1998.

6. Sheng H, Shao J, Morrow JD, Beauchamp RD and DuBois RN: Modulation of apoptosis and Bcl-2 expression by prostaglandin E2 in human colon cancer cells. Cancer Res 58: 362-366, 1998.

7. Saikawa Y, Sugiura T, Toriumi F, Kubota T, Suganuma K, Isshiki S, Otani Y, Kumai K and Kitajima M: Cyclooxygenase-2 gene induction causes CDDP resistance in colon cancer cell line, HCT-15. Anticancer Res 24: 2723-2728, 2004.

8. Liu B, Qu L and Tao H: Cyclo-oxygenase 2 up-regulates the effect of multidrug resistance. Cell Biol Int 34: 21-25, 2009.

9. Rolle CE, Sengupta S and Lesniak MS: Mechanisms of immune evasion by gliomas. Adv Exp Med Biol 746: 53-76, 2012.

10. Goldschmidt M, Peña L, Rasotto R and Zappulli V: Classification and grading of canine mammary tumors. Vet Pathol 48: 117-131, 2011.

11. Spugnini EP, Porrello A, Citro G and Baldi A: COX-2 overexpression in canine tumors: potential therapeutic targets in oncology. Histol Histopathol 20: 1309-1312, 2005.

12. Klopfleisch R, von Euler H, Sarli G, Pinho SS, Gärtner F and Gruber AD: Molecular carcinogenesis of canine mammary tumors: news from an old disease. Vet Pathol 48: 98-116, 2011.

13. Doré M: Cyclooxygenase-2 expression in animal cancers. Vet Pathol 48: 254-265, 2011.

14. Pinho SS, Carvalho S, Cabral J, Reis CA and Gärtner F: Canine tumors: a spontaneous animal model of human carcinogenesis. Transl Res 159: 165-172, 2012.

15. Howe LR: Inflammation and breast cancer. Cyclooxygenase/prostaglandin signaling and breast cancer. Breast Cancer Res 9: 210, 2007.

16. Doré M, Lanthier I and Sirois J: Cyclooxygenase-2 expression in canine mammary tumors. Vet Pathol 40: 207-212, 2003.

17. Queiroga FL, Pires I, Parente M, Gregório H and Lopes CS: COX-2 over-expression correlates with VEGF and tumour angiogenesis in canine mammary cancer. Vet J 189: 77-82, 2011.

18. Saito T, Tamura D and Asano R: Usefulness of selective COX-2 inhibitors as therapeutic agents against canine mammary tumors. Oncol Rep 31: 1637-1644, 2014. 
19. Kato M, Nishida S, Kitasato H, Sakata N and Kawai S: Cyclooxygenase-1 and cyclooxygenase-2 selectivity of non-steroidal anti-inflammatory drugs: investigation using human peripheral monocytes. J Pharm Pharmacol 53: 1679-1685, 2001.

20. Sanderson RO, Beata C, Flipo RM, Genevois JP, Macias C, Tacke S, Vezzoni A and Innes JF: Systematic review of the management of canine osteoarthritis. Vet Rec 164: 418-424, 2009.

21. Saito T, Dai T and Asano R: The hyaluronan synthesis inhibitor 4-methylumbelliferone exhibits antitumor effects against mesenchymal-like canine mammary tumor cells. Oncol Lett 5: 1068-1074, 2013.

22. Saito T, Tamura D, Nakamura T, Makita Y, Ariyama H, Komiyama K, Yoshihara T and Asano R: 4-Methylumbelliferone leads to growth arrest and apoptosis in canine mammary tumor cells. Oncol Rep 29: 335-342, 2013.

23. Saito T, Kawana H, Azuma K, Toyoda A, Fujita H, Kitagawa M and Harigaya K: Fragmented hyaluronan is an autocrine chemokinetic motility factor supported by the HAS2-HYAL2/CD44 system on the plasma membrane. Int J Oncol 39: 1311-1320, 2011

24. Gurpinar E, Grizzle WE and Piazza GA: COX-independent mechanisms of cancer chemoprevention by anti-inflammatory drugs. Front Oncol 3: 181, 2013.

25. Kardosh A, Wang W, Uddin J, Petasis NA, Hofman FM, Chen TC and Schönthal AH: Dimethyl-celecoxib (DMC), a derivative of celecoxib that lacks cyclooxygenase-2-inhibitory function, potently mimics the anti-tumor effects of celecoxib on Burkitt's lymphoma in vitro and in vivo. Cancer Biol Ther 4: 571-582, 2005.

26. Luque I and Gélinas C: Rel/NF-kappa B factors in oncogenesis. Semin Cancer Biol 8: 103-111, 1997.

27. Surh YJ, Chun KS, Cha HH, Han SS, Keum YS, Park KK and Lee SS: Molecular mechanisms underlying chemopreventive activities of anti-inflammatory phytochemicals: down-regulation of COX-2 and iNOS through suppression of NF-kappa B activation. Mutat Res 480-481: 243-268, 2001.

28. Takada Y, Bhardwaj A, Potdar P and Aggarwal BB: Nonsteroidal anti-inflammatory agents differ in their ability to suppress NF-kappaB activation, inhibition of expression of cyclooxygenase-2 and cyclin D1, and abrogation of tumor cell proliferation. Oncogene 23: 9247-9258, 2004.

29. Baeuerle PA and Baltimore D: I kappa B: a specific inhibitor of the NF-kappa B transcription factor. Science 242: 540-546, 1988.

30. Tait SW and Green DR: Mitochondria and cell death: outer membrane permeabilization and beyond. Nat Rev Mol Cell Biol 11: 621-632, 2010.

31. Darzynkiewicz Z, Bruno S, Del Bino G, Gorczyca W, Hotz MA, Lassota P and Traganos F: Features of apoptotic cells measured by flow cytometry. Cytometry 13: 795-808, 1992.

32. Hengartner MO: The biochemistry of apoptosis. Nature 407: 770-776, 2000

33. Ola MS, Nawaz M and Ahsan $\mathrm{H}$ : Role of Bcl-2 family proteins and caspases in the regulation of apoptosis. Mol Cell Biochem 351: $41-58,2011$.

34. Igney FH and Krammer PH: Death and anti-death: tumour resistance to apoptosis. Nat Rev Cancer 2: 277-288, 2002.

35. Li P, Nijhawan D, Budihardjo I, Srinivasula SM, Ahmad M, Alnemri ES and Wang X: Cytochrome $\mathrm{c}$ and dATP-dependent formation of Apaf-1/caspase-9 complex initiates an apoptotic protease cascade. Cell 91: 479-489, 1997.

36. Menter DG, Schilsky RL and DuBois RN: Cyclooxygenase-2 and cancer treatment: understanding the risk should be worth the reward. Clin Cancer Res 16: 1384-1390, 2010.

37. Holmes MD, Chen WY, Li L, Hertzmark E, Spiegelman D and Hankinson SE: Aspirin intake and survival after breast cancer. J Clin Oncol 28: 1467-1472, 2010.

38. Howe LR, Subbaramaiah K, Brown AM and Dannenberg AJ: Cyclooxygenase-2: a target for the prevention and treatment of breast cancer. Endocr Relat Cancer 8: 97-114, 2001.
39. Ristimäki A, Sivula A, Lundin J, Lundin M, Salminen T, Haglund C, Joensuu $\mathrm{H}$ and Isola J: Prognostic significance of elevated cyclooxygenase-2 expression in breast cancer. Cancer Res 62: 632-635, 2002.

40. Ranger GS, Thomas V, Jewell A and Mokbel K: Elevated cyclooxygenase-2 expression correlates with distant metastases in breast cancer. Anticancer Res 24: 2349-2351, 2004.

41. Reader J, Holt D and Fulton A: Prostaglandin E2 EP receptors as therapeutic targets in breast cancer. Cancer Metastasis Rev 30: 449-463, 2011.

42. Queiroga FL, Pires I, Lobo L and Lopes CS: The role of Cox-2 expression in the prognosis of dogs with malignant mammary tumours. Res Vet Sci 88: 441-445, 2010.

43. Queiroga FL, Perez-Alenza MD, Silvan G, Peña L, Lopes C and Illera JC: Cox-2 levels in canine mammary tumors, including inflammatory mammary carcinoma: clinicopathological features and prognostic significance. Anticancer Res 25: 4269-4275, 2005.

44. Müller AC, Handrick R, Elsaesser SJ, Rudner J, Henke G, Ganswindt U, Belka C and Jendrossek V: Importance of Bak for celecoxib-induced apoptosis. Biochem Pharmacol 76: 1082-1096, 2008.

45. Jendrossek V, Handrick R and Belka C: Celecoxib activates a novel mitochondrial apoptosis signaling pathway. FASEB J 17: $1547-1549,2003$

46. Liu X, Yue P, Zhou Z, Khuri FR and Sun SY: Death receptor regulation and celecoxib-induced apoptosis in human lung cancer cells. J Natl Cancer Inst 96: 1769-1780, 2004.

47. Liu X, Yue P, Schönthal AH, Khuri FR and Sun SY: Cellular FLICE-inhibitory protein down-regulation contributes to celecoxib-induced apoptosis in human lung cancer cells. Cancer Res 66: 11115-11119, 2006.

48. Reginato MJ, Mills KR, Paulus JK, Lynch DK, Sgroi DC, Debnath J, Muthuswamy SK and Brugge JS: Integrins and EGFR coordinately regulate the pro-apoptotic protein Bim to prevent anoikis. Nat Cell Biol 5: 733-740, 2003.

49. Sun Y, Tang XM, Half E, Kuo MT and Sinicrope FA: Cyclooxygenase- 2 overexpression reduces apoptotic susceptibility by inhibiting the cytochrome c-dependent apoptotic pathway in human colon cancer cells. Cancer Res 62: 6323-6328, 2002

50. He Q, Luo X, Huang Y and Sheikh MS: Apo2L/TRAIL differentially modulates the apoptotic effects of sulindac and a COX-2 selective non-steroidal anti-inflammatory agent in Bax-deficient cells. Oncogene 21: 6032-6040, 2002.

51. Shao J, Evers BM and Sheng H: Prostaglandin E2 synergistically enhances receptor tyrosine kinase-dependent signaling system in colon cancer cells. J Biol Chem 279: 14287-14293, 2004.

52. Sonoshita M, Takaku K, Sasaki N, Sugimoto Y, Ushikubi F, Narumiya S, Oshima M and Taketo MM: Acceleration of intestinal polyposis through prostaglandin receptor EP2 in Apc(Delta 716) knockout mice. Nat Med 7: 1048-1051, 2001.

53. Nagatsuka I, Yamada N, Shimizu S, Ohira M, Nishino H, Seki S and Hirakawa K: Inhibitory effect of a selective cyclooxygenase-2 inhibitor on liver metastasis of colon cancer. Int J Cancer 100: 515-519, 2002.

54. Timoshenko AV, Xu G, Chakrabarti S, Lala PK and Chakraborty C: Role of prostaglandin $\mathrm{E} 2$ receptors in migration of murine and human breast cancer cells. Exp Cell Res 289: 265-274, 2003

55. Chen Z, Hagler J, Palombella VJ, Melandri F, Scherer D, Ballard D and Maniatis T: Signal-induced site-specific phosphorylation targets I kappa B alpha to the ubiquitin-proteasome pathway. Genes Dev 9: 1586-1597, 1995

56. Seo KW, Coh YR, Rebhun RB, Ahn JO, Han SM, Lee HW and Youn HY: Antitumor effects of celecoxib in COX-2 expressing and non-expressing canine melanoma cell lines. Res Vet Sci 96: 482-486, 2014. 